\title{
ORAL EXPLANATIONS IN UNIVERSITY TEACHING: THE ROLE OF PROJECTOR CONSTRUCTIONS IN SPOKEN GERMAN
}

\author{
ANNA SALLER \\ University of Colorado Boulder
}

\begin{abstract}
This study explores the nature of oral explanations in German university teaching and focuses particularly on projections, which are a widely-used feature in order to guide the students' attention. Projector constructions facilitate the production and organization of complex statements and allow the speaker to draw the students' attention to crucial pieces of information. Furthermore, projections facilitate the drawing of inferences for the listener: The projector phrase opens up semantic and syntactic slots that need to be filled, so that the number of possible contents to follow is restricted. In German, the placement of the conjugated verb in the projected unit plays a crucial role for this construction.
\end{abstract}

Keywords: spoken language, German, oral explanation, projector construction, Construction Grammar

\section{RELEVANCE}

Explaining effectively is a key component in many social spheres. However, oral explanations have hardly been subject to linguistic studies so far. Because of the high impact of the speech act theory in the late 1970s and the early 1980s, explaining was examined as an isolated speech act type only (cf. Spreckels 2009:1). The processual nature of explaining was neglected, and the explanation as a final product was in focus instead (cf. Kiel 1999:16). The few theories about explanations and explaining that were developed often proclaim an idealized type of explaining (cf. Kiel 1999:16), without considering empirical material, in order to investigate thematic or context specific deviations. A study about the form of explanatory sequences considering situation and context is still a desideratum.

After giving a brief overview of the theoretical basics of explanations from a semantic point of view, I will discuss some results of a study which focused on linguistic patterns of oral explanations in university teaching, and specifically focusing on PROJECTOR CONSTRUCTIONS. While one could argue that looking at explanations without considering turns is an unsatisfactory approach for interactional linguistics, explaining and understanding go hand in hand and take place in an interactive situation in which both the speaker and listeners are physically present (cf. Ehlich 2009:16). Furthermore, face-to-face communication comprises not only verbal and physical aspects, but is also based on reception, knowledge, and inferences (cf. Fiehler 2015:373). Since the term PROJECTOR CONSTRUCTION (PC) is borrowed from the theoretical framework of 
CONSTRUCTION GRAMMAR (CxG), I will briefly explain why the $\mathrm{CxG}$ perspective is an appropriate one when talking about spoken language, and what a PC looks like. Afterwards, I will show how PCs manifest themselves in oral explanations in university teaching, how PCs in German explanations are significant, and how they fulfill an important function in guiding the students' attention to crucial parts in an explanatory sequence.

\section{THE BASICS OF EXPLAINING}

The verb ERKLÄREN ('explain') is used in a very broad sense in everyday conversation. Klein subdivided the concept of explaining into three semantic classes: ERKLÄREN-WAS ('explainingWHAT'), ERKLÄREN-WIE ('explaining-HOW'), and ERKLÄREN-WARUM ('explaining-WHY'). Explaining for instance what an idiom means is explaining-WHAT, if someone explains how to use a computer program, it is explaining-HOW, and explaining why glaciers are melting is explainingWHY (cf. Klein 2009:25). The common goal of all these types of explaining is ensuring comprehension. The classification into those three types is based on the question one can use to ask for the explanandum (the phenomenon explained). The WHAT type also comprises questions starting with who or which and is targeted at characteristic traits of the explanandum. The HOW type asks for the modality of processes, and the WHY type gives a cause or reason for something (cf. Klein 2009:26).

In German, the verb ERKLÄREN is often used synonymously to ERLÄUTERN ('elucidate') and BEGRÜNDEN ('give reasons'). Those terms, however, can be semantically distinguished: The communicative function of ERLÄUTERN (unless that of ERKLÄREN) is not the systematic creation of knowledge, but adding supplementary knowledge that is necessary in the specific context of action (cf. Morek 2012:31). Therefore, ERLÄUTERN is rather reparative in nature. BEGRÜNDEN, too, does not primarily create new knowledge; instead, it updates and rearranges already existing elements of knowledge (cf. Morek 2012:31). However, it is difficult to draw a clear line between BEGRÜNDEN and ERKLÄREN-WARUM (in Klein's semantic distinction), because both rearrange knowledge by giving a reason or causal relation.

From a receptive perspective, the explanation process can be divided into three cognitive processes: analysis, synthesis, and syncrisis (from Greek syn 'together' and krinein 'choose, arrange) (cf. figure 1). During analysis, the explanandum is split into its elements and they are put into a certain relation. During synthesis, the explanandum is inserted into a superordinate complex 
of knowledge. The synthesis is a central criterium, because it distinguishes explaining from other related speech acts. However, it is the syncrisis that makes an explanation successful, since here the new knowledge is anchored in the recipient's network of knowledge (cf. Hohenstein 2006:87).

FIGURE 1. THE THREE COGNITIVE PROCESSES OF RECEPTION DURING AN EXPLANATION

(cf. Hohenstein 2006:87ff.)

\section{Analysis}

splitting the

explanandum into its

elements

\section{Synthesis}

explanandum is inserted into a superordinate complex of knowledge

\section{Syncrisis}

new knowledge is anchored in the recipient's network of knowledge

\section{METHODOLOGY}

In 2016, I recorded six classes at a University (Regensburg, Germany) in order to analyze oral explanation patterns in German university teaching. From these recordings (three in German linguistics and three in German literature classes), I isolated explanatory sequences and transcribed them based on $\mathrm{GAT}^{1}$ conventions with some minor variations (contrary to most conventions, I used regular punctuation, since this facilitated the recognition and analysis of the PCs examined here). The individual sequences varied between 4:24 and 8:45 minutes in length, since the teachers varied in speaking rate and pause duration. The final corpus of the extracted explanatory sequences was 42:39 minutes in length. All classes were introductory classes (no lectures) in which the explanation of crucial contents for the particular fields was essential. The teachers recorded were balanced in ages (in their 30s, 40s, 50s and 60s), sexes, and academic status ( $\mathrm{PhD}$, post-doctoral, and tenure-track positions).

\section{SPOKEN LANGUAGE AND THE CONSTRUCTION GRAMMAR PERSPECTIVE}

The study aimed at investigating which strategies teachers employ in order to create cohesion in oral explanations, and whether there are differences between those strategies in linguistics and in literary studies classes. The focus was on a structure which is referred to as PROJECTION or PROJECTOR CONSTRUCTION in construction grammar and in interactional linguistics. Oral

${ }^{1}$ GAT = Gesprächsanalytisches Transkriptionssystem (Transcription system for analyses of spoken interactions); developed by Selting et al. 1998 . 
explanations take place in a face-to-face situation, which means that the sequences should be analyzed from an interactional perspective. A purely structural perspective works for written language, but not for the structure of spoken language. Language routines and grammar evolve by daily language use - due to grammaticalization, grammar changes all the time in our daily interactions and is never solidified (cf. Ford et al. 2003:119), which is why traditional grammars are not suitable for the description of spoken interaction. For instance, there are three assumptions in traditional grammar theories that do not work for spoken interactions:

i. Clause assumption: A clause is a complete syntactic unit that expresses one proposition and that consists of at least a subject and a predicate.

ii. Formality assumption: Syntactic rules are formal, abstract, and generally valid. They apply for all elements of the respective grammatical category (e.g. word class, clause type etc.) or for respective grammatical relations (syntactic functions etc.)

iii. Compositionality assumption: The meaning of a phrase or clause is compositional. This means that the meaning of a phrase or clause is made up by the sum of the lexical meanings of its word and the syntactic structure in combination (cf. Deppermann 2006:44).

CONSTRUCTION GRAMMAR $(\mathrm{CxG})$ developed out of the recognition that those premises are inadequate for spoken language (cf. Deppermann 2006:47) and is therefore increasingly used for interactional purposes. $\mathrm{CxG}$ is a collective term for a number of theoretical conceptions about grammar that developed under mutual influence (e.g. Fillmore et al. 1988; Kay 1997, 2002; Kay/Fillmore 1999; Goldberg 1995; Langacker 1987; Croft 2001)². CxG views a construction as a form-meaning pairing in which the meaning is not compositional (cf. Michaelis 2006:73). The formal part of the construction is the formal realization in a scheme or syntactic pattern and comprises phonological patterns like prosody and intonation in addition to morphosyntactic patterns. The meaning part consists of both semantic and pragmatic meaning. Since each of the

\footnotetext{
2 The term CONSTRUCtion Grammar $(\mathrm{CxG})$ was coined by Charles Fillmore and Paul Kay (Fillmore et al. 1988; Kay 1997; Kay/Fillmore 1999). They studied particularly idiomatic phenomena of single languages. Adele Goldberg (1995) tied in with Lakoff's Cognitive Linguistics (Lakoff 1987) and his cognitive view on categorization. Ronald Langacker's Cognitive Grammar (Langacker 1987) is a comprehensive language theory that describes general cognitive and symbolic principles. Finally, William Croft developed Langacker's approach further to a Radical Construction Grammar (Croft 2001), according to which syntactic knowledge is exclusively represented by grammatical constructions.
} 
aforementioned elements are crucial to understanding the use of projections in oral explanations, a perspective that is aligned with basic assumptions of $\mathrm{CxG}$ is reasonable here. However, while $\mathrm{CxG}$ has a strong cognitive perspective, conversation analysis (CA) focuses on interaction, which is why most studies in interactional linguistics have focused on semantic and pragmatic aspects so far (cf. Deppermann 2006:59), but not in connection to structural features. Furthermore, it has not yet been investigated how certain constructions are actually used in particular contexts or genres of spoken interaction (cf. Günthner 2006:98). Thus, this study explores PCs in the context of university teaching.

\section{PROJECTIONS IN ORAL EXPLANATIONS}

A projection is a structure which consists of two parts: The first part (A) is the projector phrase which projects the second part (B) semantically and phonetically as well as syntactically (cf. Günthner 2008:86). In order to understand why those projections are significant here, one must consider that in German, the position of the conjugated verb depends on whether it occurs in a main or in a subordinate clause. In a main clause, the conjugated verb (which might be an auxiliary in perfect tense or in passive voice, or a modal verb) is in second position, regardless of what is in first position (unlike English, where the verb usually follows the subject or agent). In a subordinate clause, the conjugated verb is in the last position. The projector phrase $\mathrm{A}$, which announces $\mathrm{B}$, is placed in square brackets. The main verb in A is underlined, because it is crucial for the projection - it requires an obligatory complement which is realized in B as a complement clause. Even if B is supposed to be a "subordinate" clause according to traditional grammar, it has a $V_{2}$ pattern.

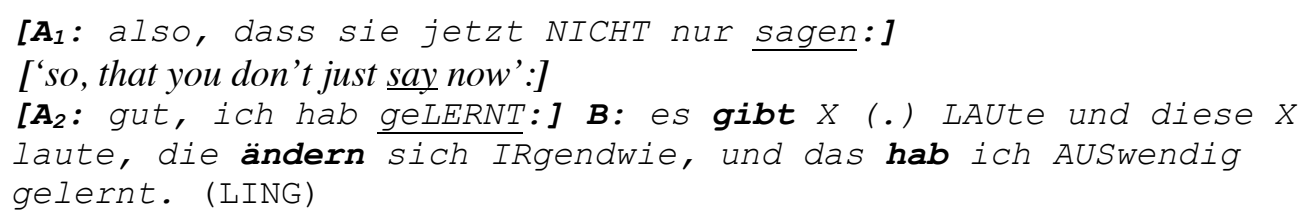

['good, I have learnt':] 'there are X (.) sounds und those X sounds, they change somehow, and I have learnt that by heart.'

[A: ICH hab noch geLERNT:] B: da gibt es eine SOgenannte AUSlautverHÄRtung=ja. (LIT)

['I have still learnt':] 'There is a so-called final-obstruent devoicing=ya.'

About a century ago, the B parts as shown above used to be called "UNEINGELEITETER NEBENSATZ" ('unintroduced subordinate clause') (Behaghel 1928), because the formulation in 
written language for B would have been introduced by a subordinating conjunction (here: dass) with the verb in final position (compare $3 b, 4 b$ ):

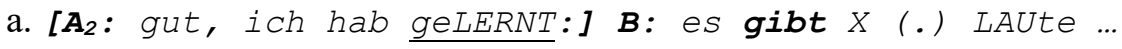
b. Gut, ich habe gelernt, dass es $x$ Laute gibt ...
a. [A: ICH hab noch geLERNT:] B: da gibt es eine Sogenannte AUSlautverHÄRtung $=j a$.
b. Ich habe noch gelernt, dass es da eine sogenannte Auslautverhärtung gibt.

In our examples, there is neither a subordinating conjunction nor is the verb in final position. And it is actually the B part of the construction that carries the relevant information (the central proposition), so one could argue that semantically part B is not subordinate at all. This reveals the flaws in the notion of "main" and "subordinate" clauses, which are very much aligned to traditional grammar views based on written language. Since B has the same syntactic structure as a main clause in German, it was later called “ABHÄNGIGER HAUPTSATZ” ('dependent main clause') (Auer 1998), which seems to be contradictory in itself. I argue that B is not dependent on part A, but rather the projector phrase raises the awareness of the recipient for the following B part as it carries crucial information. The projector phrase is syntactically, semantically, and intonationally incomplete and opens up slots. The incompleteness in the projector phrase draws the attention of the recipients to exactly those slots that are filled by the B part. Thus, the projector phrase plays an important role on a metacommunicative level, but it is does not contribute to the proposition conveyed in B.

The basic units of spoken language are rarely complete sentences as presented in traditional grammar based on written language. Instead, the basic units are intonationally and semantically coherent and functional units that usually just carry one new piece of information (cf. Tomasello 2003:4). Auer found that in constructions that consist of two parts (like PROJECTOR CONSTRUCTIONS (PCs)), the transition between A and B is usually marked by a pause or an increase in pitch (cf. Auer 1997:61). This increase in pitch along with rising intonation indicates phonetically that the construction is not complete yet, and thus, it secures the right to continue speaking. 
Despite the fact that PCs clearly consist of two parts (which is a typical feature of spoken language; cf. Fiehler 2015:3913), the use of terms like "dependent" and "independent" or "subordinate" seems to be inappropriate for spoken language. First of all, the notion of dependence is one of a hierarchical organization of syntax which is based on traditional views of grammar for written language, and second, utterances are constantly under construction. The notion of a hierarchical structure makes sense for written language production where a whole sentence is planned beforehand. In spoken interaction, however, the planning of utterances happens in every moment of speaking. This BOTTOM-UP approach to speech production is supported and confirmed by psycholinguistic findings (cf. Rickford et al. 2010:55). The temporally undelayed production and reception of utterances during spoken interaction is also called ONLINE SYNTAX or INCREMENTAL SYNTAX (cf. Auer 2000, 2007). The immediate production during speaking requires different strategies than for writing. Thus, the two basic operations for spoken language are projections and retractions (cf. Auer 2000:47). The use of the type of PC discussed here allows $^{4}$ the speaker to (i) conceptualize the main information, (ii) secure his right to continue speaking, and (iii) draw the attention to the slots that are opened up by the projector phrase. The induced control of the recipients' expectations works on a syntactic, semantic, and intonational level.

There were hardly any differences in the number of PCs between explanations in linguistics and in literary studies in my corpus: There were 23 PCs in linguistic explanations, and 27 in literary studies explanations (which makes 50 PCs in total). Those 50 PCs allocated to 6 recordings means 8.33 PCs on average per explanatory sequence. The average length of an explanatory sequence

${ }^{3}$ PROJECTOR CONSTRUCTIONS are very similar to what Fiehler calls OPERATOR-SCOPUS STRUCTRE: This is a spoken unit consisting of two parts. The SCOPUS is a full proposition, and the OPERATOR is a preceding unit that refers to the SCOPUS and acts as an "instruction manual" for the recipient on a metacommunicative level, which means that it gives the recipient a hint on how to understand the following utterance. (cf. Fiehler 2015:386, 391).

${ }^{4}$ There are many different types of PROJECTOR CONSTRUCTIONS or projections. They can be lexically more solidified like Die Sache ist constructions in German (cf. Günthner 2008), but they can also be purely structural like 'pseudocleft' constructions (cf. ibid). In German, an inflected adjective only occurs within a NP and thus projects a noun; a preposition requires and projects a certain case; a verb in a certain context projects the number of complements depending on its valency). German is a language which is rich in projections compared to Japanese which is poor in projections but uses other strategies in conversation (cf. Auer 2007:4; Ford et al. 2003:130f.). There is a general tendency that languages that employ more synthetic strategies (inflection) are richer in projections, and languages that employ more analytic strategies are poorer in projections. 
was 6:35 minutes, which means that teachers used on average 1.31 PCs per minute of explanatory sequence (or at least 1 PC per minute for explaining).

\subsection{FORM OF PROJECTED UNITS}

As discussed above, the crucial element of this construction is that part B does not show the typical features of a "subordinate" clause - neither structurally, nor semantically. Looking at the projected units more closely, one finds that they do not necessarily show a $\mathrm{V}_{2}$ pattern as well, but express questions (examples 5 and 6) and units with no explicit verb at all (examples 7 and 8):

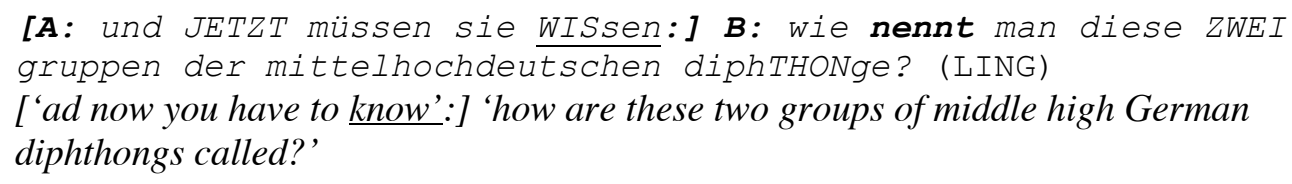

[A: sie SCHAUen sich sozusagen das ENde an:] B: wie KUCKT das ENde eines VERses aus? (LIT)

['Yu look, as it were, to the end':] How does the end of the verse look like?'

[A: bei [ts] haben wir die geschichte AUCH:] B: BEIDE male dentAL, (-) ERST plosiv, DANN frikativ. (LING) ['e have the story with [ts], too':] 'Both times dental, first plosive, then fricative.'

[A: ich habe das DESwegen so AUSführlich geMACHT, um ihnen einen beGRIFF nochmal NAHEzubringen, den sie EH schon mal LETZTE sitzung KURZ in den RAUM gestellt haben:] B: die kaDENZ. (LIT) ['I made this so detailed with the purpose to confront you with a term again which you already mentioned (literally: 'placed into the room') once last class':] 'cadence.'

This makes the term "ABHÄNGIGER HAUPTSATZ” seem even more unsuitable, particularly for the questions. However, in constructions like 7 and 8, the B parts are indeed dependent on the projector phrase, and the whole construction works differently: Here, it is not the main verb in the projector phrase that opens up a syntactic slot which needs to be filled, but it is a noun phrase (NP). In order to guide the recipients' attention, the speaker uses a substitution for B in the form of a NP in the projector phrase. In example 7, the Geschichte ('story') refers to the earlier posed question of what an affricative is. This question was answered for [pf] before (as a transitional sound from a plosive to a fricative), and now the story is the same for [ts]: 'Both times dental, first plosive, then fricative'. In example 8, Kadenz ('cadence') is substituted by einen Begriff ('a term') in the projector phrase. In those examples without an explicit verb in B, one can also speak of 
RETRACTION, because B is reduced to the greatest degree, but at the same time refers back to a crucial semantic slot that was opened up in A. Those examples show how PROJECTION and RETRACTION can go hand in hand with each other. Figure 2 shows the distribution of $\mathrm{V}_{2}$ pattern, question pattern, and verbless pattern in the projected units within the corpus.

FIGURE 2. VERB POSITION PATTERNS IN THE PROJECTED UNITS (B)

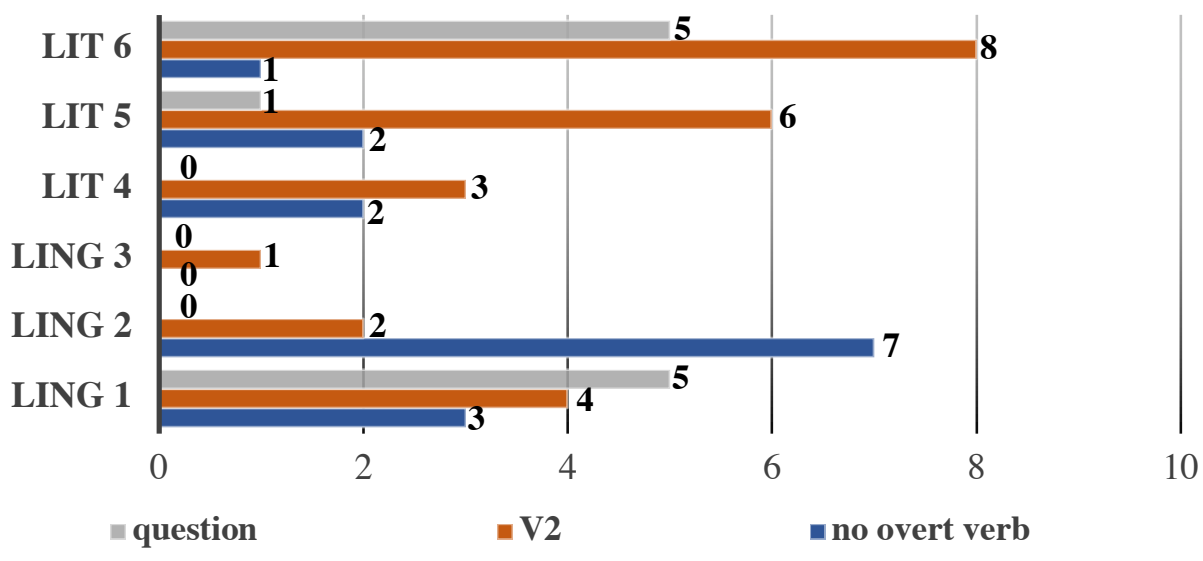

In total, 24 out of 50 units showed $\mathrm{V}_{2}$ pattern (48\%), 11 out of 50 were questions $(22 \%)$, and 15 out of 50 did not have an overt predicate (30\%). All teachers use PCs with $\mathrm{V}_{2}$ pattern. 5 out of 6 teachers use verbless structures, and 3 out of 6 teachers use questions as well. Questions in projected units are therefore the least frequently used forms in projected units, and all questions are question-word interrogatives. There is only one speaker (LING explanation) who uses verbless units in $\mathrm{B}$ more often than the $\mathrm{V}_{2}$ pattern, which might be an idiosyncratic feature. Those retractive constructions with verbless B parts have a strong binding force, because A and B are strongly dependent on each other: A does not make sense without $\mathrm{B}$, because there is a crucial semantic gap in it - and the semantic gap, which is B, does not make sense on its own as well, because it is the "missing piece" in the projector phrase. A few more examples shall illustrate that:

[A: MANCHmal werden die auch TEnues genannt, DESwegen dieser beGRIFF hier:] B: der TEnuesverschiebung. (LING) ['Sometimes, they are also called tenues, therefore this term here': ] 'tenues shift.'

[A: dann ein NÄCHStes BEIspiel:] B: EM (-) baRoCke embleMAtik. (LIT) ['Then another example': ] 'baroque emblematics.' 


\subsection{FORM OF PROJECTOR PHRASES}

As is typical for PCs, which consist of a projector phrase A and a projected unit B, the conjugated verb in part $\mathrm{B}$ is never in final position. However, the projector phrase (which, according to traditional grammar views is a "main" clause) can have the verb in final position.

FIGURE 3. VERB POSITION PATTERNS IN THE PROJECTOR PHRASES (A)

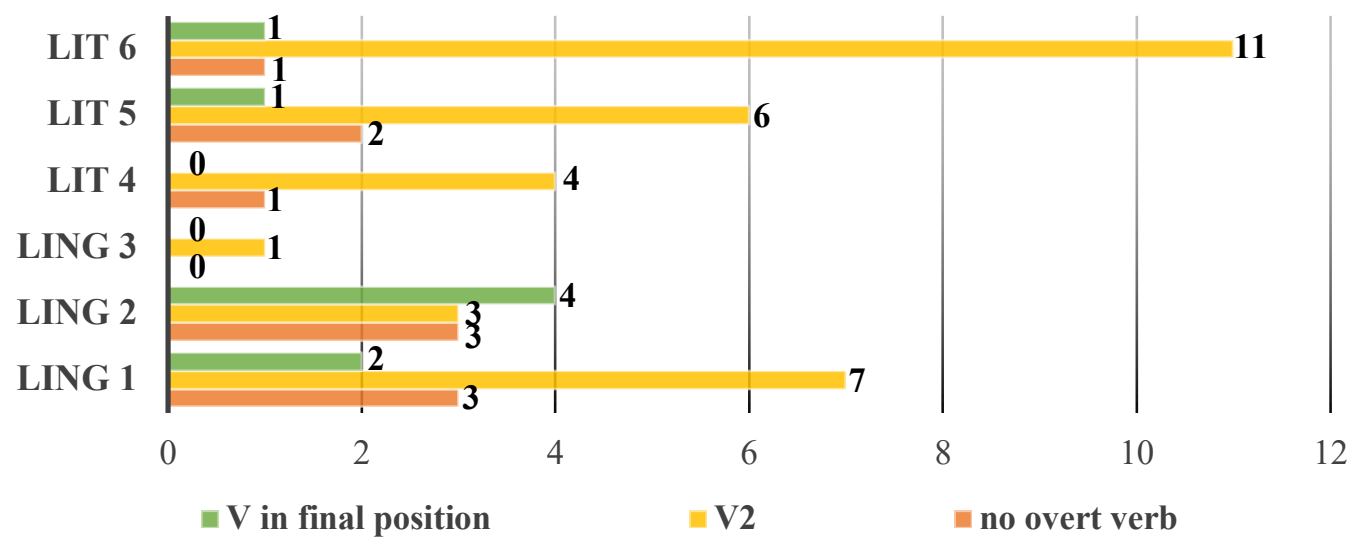

Figure 3 shows that the $V_{2}$ pattern is still the most frequent one in the projector phrase (32 out 50, which makes up 64\%), followed by verbless units (10 out of 50, which makes up 20\%), and units with the verb in final position occur in $16 \%$ of all cases ( 8 out of 50 ). In those cases with the verb in final position, the projector phrase was either introduced by a subordinating conjunction (dass 'that', wenn 'when'/ 'if', weil 'because', was 'what'[RELATIVIZER]) or it was an infinitive construction ( $u m$... zu '(in order) to'). Examples 11 and 12 illustrate this with wenn:

[A: wenn sie jetzt SAgen:] B: WIE(.)SO schreiben die da ein <u> und sprechen ein [I]? [-ja, keine AHnung, das machen wir AUCH.] (LING) ['If you say now': ] 'Why do they write an <u> and speak an [l]?' [ - 'ya, no idea; we do that, too.']

$$
\begin{aligned}
& \text { [A: wenn sie IRgendwo sehen:] B: aHA, da ist ein [p], das beTROFfen } \\
& \text { ist, [dann HEISST das ERSTmal noch ! GAR! nichts.] (LING) } \\
& \text { ['When you see somewhere': ] 'ah, there is a [p] which is affected,' ['that does not mean } \\
& \text { anything provisionally.] }
\end{aligned}
$$

Looking at the construction as a whole, it turns out that not all constructions have the form $\left[\left[\mathrm{V}_{2}:\right] \mathrm{V}_{2}\right]$, but it is the most common form. The verb in final position occurs in $64 \%$ of all cases in 
part $\mathrm{A}$ and in $48 \%$ of all cases in B. In example 12, B is followed by another unit in square brackets, because whenever there is a unit introduced with wenn, it is followed by another unit introduced by dann. The wenn ...-dann... ('when...-then...') construction is a typical structure that is found very often in explanations (cf. Morek 2012:29), since it expresses a regularity in a certain condition.

\subsection{LEXICAL, SYNTACTIC, AND PRAGMATIC CONDITIONS FOR PROJECTIONS}

The observation that $\mathrm{V}_{2}$ patterns following a "main clause" occur much more frequently in spoken than in written German is in fact not new: Auer (1998) compared the Freiburg Corpus, created specifically to study the syntax of spoken language, to the BZK (Bonn-KölnerZeitungskorpus 'Bonn-Cologne Newspaper Corpus' for written language), and found that the $\mathrm{V}_{2}$ pattern 'dependent main clause' occurs significantly more frequently in spoken German, and that it correlates with specific semantic fields: They are often used after VERBA SENTIENDI and VERBA DICENDI (verbs of reception and communication), for instance hören ('hear'), denken ('think'), or sagen ('say'). However, $\mathrm{V}_{2}$ patterns in B are usually not compatible with A parts that use verbs of wanting and causing, for instance veranlassen ('to cause'), wollen ('to want'), or verhindern ('to prevent') (cf. Auer 1998:8). Indeed, the PCs in the analyzed data mostly used verbs in the projector phrase that express a form of thinking, remembering, communicating etc.

A 'dependent main clause' is also not possible after negation. Example 13 (constructed) illustrates that syntactic negation is not compatible with a following $\mathrm{V}_{2}$ pattern. 13a is a positive statement ('I think') that works perfectly fine with a $V_{2}$ pattern, but $13 \mathrm{~b}$, which is just the negation of $13 \mathrm{a}$, does not work with this pattern.
a. [ich denke:] es wird morgen regnen.
['I think': ] 'It will rain tomorrow.']
b. *? [ich denke nicht:] es wird morgen regnen.
*? ['I don't think': ] 'It will rain tomorrow.']

However, it is unclear whether it is the syntactic construction that makes $13 \mathrm{~b}$ sound awkward, or whether it is the negative semantics. Example 14 (constructed) indicates that it is more likely that the negative semantics is not compatible with the $V_{2}$ pattern, because here there is no syntactic 
negation, but rather verbs which have an inherently negative semantics ('to doubt', 'to be false'). In those cases, the subordinating conjunction dass with verb in final position is required.

a. [ich hoffe:] es gibt ein leben nach dem tod.

['I hope':] 'there is a life after death.']

b. *? [ich bezweifle:] es gibt ein leben nach dem tod.

*? ['I doubt': ] 'there is a life after death.']

a. [es ist wahr:] in seattle regnet es viel.

['It is true': ] 'It rains a lot in Seattle.']

b. *? [es ist falsch:] in seattle regnet es viel.

*? ['It is false': ] 'It rains a lot in Seattle.']

Interestingly, comparing German to English, it seems to be more common in English as well to insert the subordinating conjunction that after projections with negative semantics (i.e. I doubt that there is a life after death; It is false that it rains a lot in Seattle).

Furthermore, there are important pragmatic reasons which invoke projected units with $\mathrm{V}_{2}$ patterns. Units that are introduced by subordinating conjunctions are more likely to contain already familiar content, and are thus pushed into the background, which means that the first part of the construction is in the focus (cf. Auer 1998:11). Conversely, if the second part is not introduced by a subordinating conjunction but shows a $\mathrm{V}_{2}$ pattern, the attention is drawn to this second part (cf. ibid). This might even explain why utterances with a negative semantics often occur with subordinating conjunctions: We do not negate random facts that we consider to be false, but only those ones of which we can assume that out communication partners are already familiar with, and that are relevant to them (cf. Auer 1998:11). In other words: The new and relevant information is the negation in the A part itself, and the thing being negated in B is already familiar information, that is moved away from the focus.

Similarly, if the first part of the construction already implies a certain knowledge, attitude or mental action of the speaker (e.g. staunen 'to wonder', gut finden 'to like', verzeihen 'to forgive, sich wundern 'to be surprised'), it is more likely to be followed by a unit with a subordinating conjunction and verb in final position. This is because the relevant information is implied in the first part and the first part is in focus, not the second one, as example 16 shows. 

a. ich wundere mich, dass du hier bist.
'I am surprised that you are here.'
b. *? [ich wundere mich:] du bist hier.
*? ['I am surprised': ] 'You are here.'

The assumption that the $\mathrm{V}_{2}$ pattern is used to guide the recipient's attention is also backed by the fact that a construction of the form $\left[\left[\mathrm{V}_{2}:\right] \mathrm{V}_{2}\right]$ does not allow the second part to be moved in front of the first part ${ }^{5}$, which is possible if the same utterance has the form $\left[\left[\mathrm{V}_{2}:\right] \mathrm{V}_{\text {final }}\right]$ :
a. ich erkenne, dass die zeit reif ist.
'I realize that the time is ripe.'
a'. dass die zeit reif ist, erkenne ich.]
b. [ich erkenne:] die zeit ist reif.
['I realize': ] 'The time is ripe.'
b'. * die zeit ist reif, erkenne ich.

17a' illustrates that the clause which is introduced by a subordinating conjunction and has the verb in final position can be moved into the PREFIELD (the slot in front of the conjugated verb), whereas for $17 \mathrm{~b}$ ' with the clause in $\mathrm{V}_{2}$ structure, this is impossible. The fact that the structure with subordinating conjunction and $\mathrm{V}_{\text {final }}$ can be topicalized means that there is less focus on this part, since the topic/theme carries usually familiar or less relevant information. The $\mathrm{V}_{2}$ pattern, however, can not be topicalized, which is an indicator that the information is considered to be important, and that this structure is used to shift the focus on this part of the construction. This observation fosters the hypothesis that PCs of the type with 'dependent main clause' are used to draw the recipients' attention to the second part of the construction (as well as the fact that the first part builds up semantic and syntactic expectations in the hearer by the slots it opens up).

\footnotetext{
5 There is the tradition in German linguistics to describe constituent order in a sentence with the theory of topological fields. Since German is considered to be a $V_{2}$ language, the syntactic phrase in front of the conjugated verb is called VORFELD ('prefield'), the phrase(s) between the first and the second (if applicable) part of the predicate (which can consist of LINKER and RECHTER SATZKLAMMER ('left and right sentence brace') in perfect tense, constructions with modal verbs, passive etc.) is called MITTELFELD ('middle field'), and everything following the right sentence brace is called NACHFELD ('afterfield') (usually subordinate clauses in written language, and obliques in spoken language if there were too many obliques and complements in the middle field).
} 


\subsection{INDIRECT CHANGE OF PERSPECTIVE}

The interactional nature of oral explanations also becomes obvious in what I call "indirect change of perspective". This means that the teacher formulates an utterance from the perspective of the recipients, which is discernable in the use of the pronouns. By doing that, the teacher leaves the role of disseminator of knowledge and assumes the role of the students. Those changes of perspective very often occur in B parts of PCs. Example 18 illustrates that well:

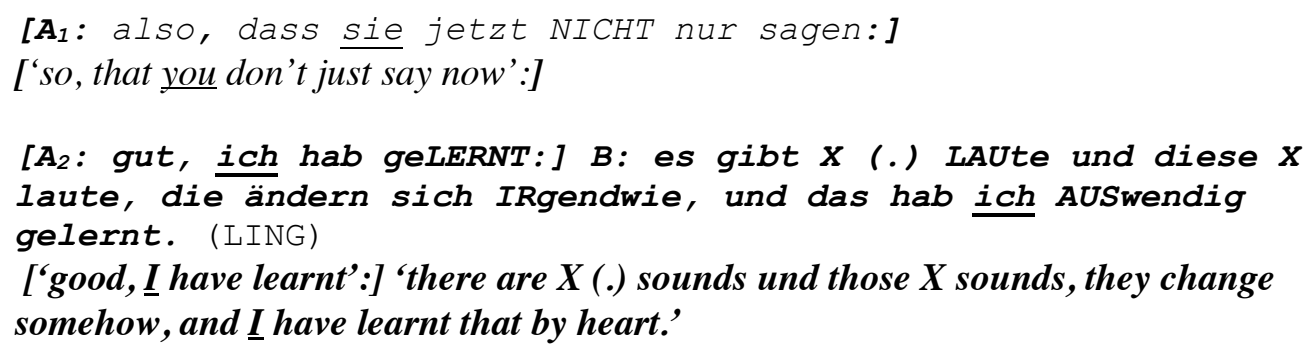

In $\mathrm{A}_{1}$, the students are directly addressed as Sie'/you', which explicitly excludes the speaker. $\mathrm{A}_{1}$ is here the projector phrase for $\left[\left[\mathrm{A}_{2}:\right] \mathrm{B}\right]$, which is an indirect change of perspective because it articulates what the students are supposed to think. In $\left[\left[\mathrm{A}_{2}:\right] \mathrm{B}\right]$, the pronouns switches from Sie/'you' to ich/'I'. Within the indirect change of perspective, $\mathrm{A}_{2}$ serves as a projector phrase for $\mathrm{B}$ as well, so that the whole structure is $\left.\left[\left[\mathrm{A}_{1}:\right] \mathrm{A}_{2}:\right] \mathrm{B}\right]$. The personal pronoun $i c h$ (' $\mathrm{I}$ ') does not refer to the teachers themselves, but to each individual student from their perspective. Additionally, all the questions that occur in B parts (which are 22\%, see 5.1) are changes of perspective, because they express what students are supposed to ask themselves. The previously provided examples 5 and 11, reproduced below, illustrate this well:

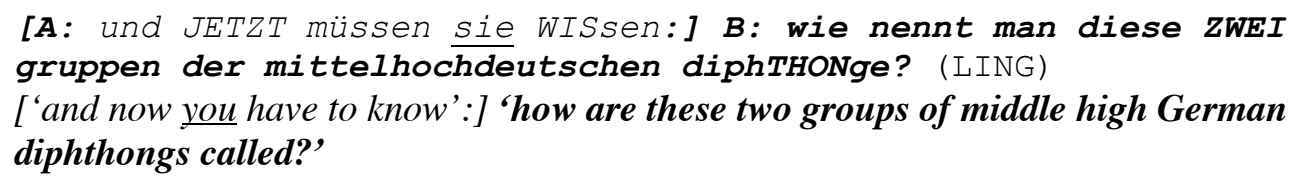

[A: wenn sie jetzt SAgen:] B: WIE(.)SO schreiben die da ein 〈u> und sprechen ein [1]? [- ja, keine AHnung, das machen wir AUCH.] (LING) ['If you say now': ] 'Why do they write <u> and speak [l]?' [ - 'ya, no idea; we do that, too.']

Articulating potential or supposed thoughts of the students can help them process the explained content and create mental coherence. The whole corpus showed a total of 18 indirect changes of 
perspective, of which 15 were used in projected unit, meaning that in $83.3 \%$ of all changes of perspective it follows a projector phrase. By doing this, the mental processing is facilitated in two ways: First, by opening up slots and thus guiding the recipients' attention, and second, by assuming the role of the student and articulating content from their perspective.

\section{FIGURE 4. INDIRECT CHANGE OF PERSPECTIVE IN PROJECTED UNIT WITHIN PCS}

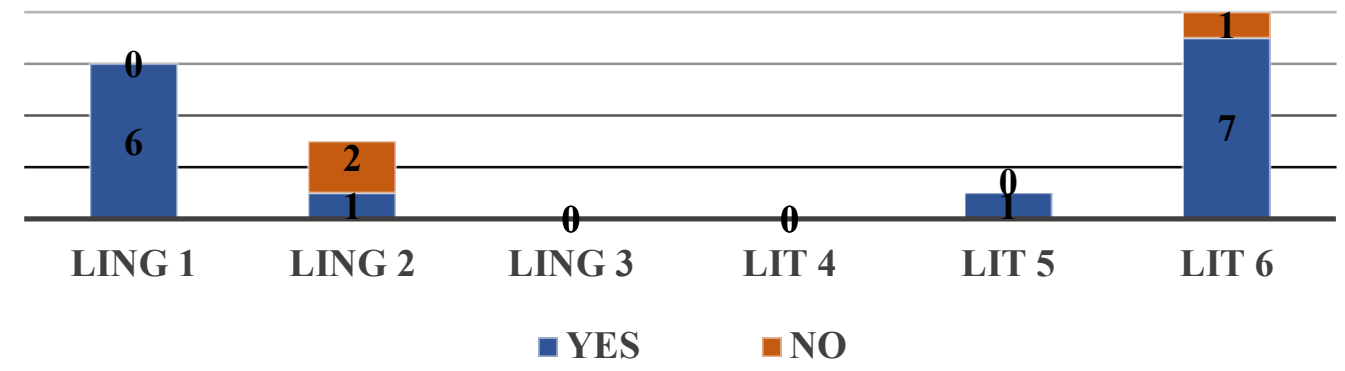

\section{CONCLUSION}

In spoken language, coherence is created differently in both production and perception than in written language, and the speakers use different cohesive strategies. In oral explanations in university teaching, PROJECTOR CONSTRUCTIONS are used frequently, and the view of this structure as a CONSTRUCTION includes not only the syntactic structure, but also semantics, pragmatics, and prosody which interact closely with one another. Even if PCs are analyzed in their two parts here, the two units form one construction, and the PC can only display its effect (to guide one's attention) in spoken interaction as a whole. This is why the view of German syntax as consisting of matrix and subordinate clauses is not unproblematic when talking about spoken language. The reasons why PCs are used so frequently in oral explanations are to be found in their cognitive and interactive functions: For the speaker, it is easier to produce and to organize complex statements, especially given the fact that speech is produced ONLINE, and conceptualization is an incremental and ongoing process (cf. Auer 2000). By using projections, the speakers secure their right to continue speaking. From the receptive perspective, PCs facilitate the drawing of inferences: The projector phrase opens up specific slots that need to be filled, so that the number of possible contents to follow is restricted (cf. Günthner 2008:108).

In university teaching, PCs occur in various forms. The $\left[\left[\mathrm{V}_{2}:\right] \mathrm{V}_{2}\right]$ construction is the most common one, but there are also $\mathrm{V}_{\text {final }}$ as well as verbless projector phrases (A). The projected units 
(B) can be in question form as well, but they do not have a $\mathrm{V}_{\text {final }}$ pattern (if they do, they are not considered a PC, but a hierarchical structure following the rules of written language). When B occurs as a verbless unit, it usually does not fill a syntactic gap opened up by the valency of the main verb in A, but it substitutes a less specific NP in the projector phrase that is used to draw the recipients' attention to $\mathrm{B}$. Another interesting observation is that the teachers sometimes form utterances from the students' perspective, which raises the potential for identification in them. In more than $80 \%$ of those cases, the change of perspective occurs in part B within a PC. The suggestion that PCs are used to guide the students' attention is supported by some restrictions to PCs: Part A cannot be negated, because a negation is always in focus, which is contradictory to a PC whose aim is to shift the focus to part B. Part B, in turn, cannot be topicalized, because topicalization would lead to reduction in focus. If B were phrased as a "subordinate clause" with a $\mathrm{V}_{\text {final }}$ pattern, however, it could be topicalized, but then, it is out of focus. This shows that the verb placement in German is crucial in order to either put units in focus or to push them into the background. This study shows how PCs are systematically used in university teaching to guide the students' attention to crucial pieces of information in part B, and how oral explanations in German exploit a different strategy with regard to the syntactic structure than written German does.

\section{REFERENCES}

Auer, Peter. 2007. Syntax als Prozess. Gespräch als Prozess, ed. by Heiko Hausendorf, 95-124. Tübingen: Narr. Online: http://www.inlist.uni-bayreuth.de/issues/41/InLiSt41.pdf, 1-35.

Auer, Peter. 2000. On-line Syntax - oder: was es bedeuten könnte, die Zeitlichkeit der mündlichen Sprache ernst zu nehmen. Sprache und Literatur 85. 43-56.

Auer, Peter. 1998. Zwischen Parataxe und Hypotaxe: Abhängige Hauptsätze im gesprochenen und geschriebenen Deutsch. Zeitschrift für Germanistische Linguistik 26. 284-307.

Auer, Peter. 1997. Formen und Funktionen der Vor-Vorfeldbesetzung im gesprochenen Deutsch. Syntax des gesprochenen Deutsch, ed. by Peter Schlobinski, 55-92. Opladen: Westdeutscher Verlag.

Behaghel, Otto. 1928. Deutsche Syntax. Eine geschichtliche Darstellung. Band III: Die Satzgebilde. Heidelberg: Winter.

Croft, William. 2001. Radical Construction Grammar. Oxford: Oxford University Press.

Deppermann, Arnulf. 2006. Construction Grammar - eine Grammatik für die Interaktion? Grammatik und Interaktion. Untersuchungen zum Zusammenhang von grammatischen 
Strukturen und Gesprächsprozessen, ed. by Arnulf Deppermann, Reinhard Fiehler and Thomas Spranz-Fogasy, 43-66. Radolfzell: Verlag für Gesprächsforschung.

Ehlich, Konrad. 2009. Erkären verstehen - Erklären und Verstehen. Erklären.

Gesprächsanalytische und fachdidaktische Perspektiven, ed. by Rüdiger Vogt, 11-24.

Tübingen: Stauffenburg.

Fiehler, Reinhard. 2015. Syntaktische Phänomene in der gesprochenen Sprache. Handbuch Satz, Äußerung, Schema (= Handbuch Sprachwissen 4), ed. by Christa Dürscheid and Hans Georg, 370-395. Berlin et al.: De Gruyter.

Fillmore, Charles; Paul Kay; Mary Catherine O'Connor. 1988. Regularity and Idiomaticity in Grammatical Constructions: The Case of let alone. Language 64, vol. 3. 501-538.

Ford, Cecilia; Barbara Fox; Sandra A. Thompson. 2003. Social interaction and grammar. The New Psychology of Language: Cognitive and Functional Approaches to Language Structure, vol. 2, ed. by Michael Tomasello, 119-143. Mahwah, NJ: Routledge.

Goldberg, Adele. 1995. Constructions. Chicago, IL: University of Chicago Press.

Günthner, Susanne. 2008. Projektorkonstruktionen im Gespräch: Pseudoclefts, die Sache istKonstruktionen und Extrapositionen mit es. Gesprächsforschung 9. 86-114.

Günthner, Susanne. 2006. Grammatische Analysen der kommunikativen Praxis - ,Dichte Konstruktionen' in der Interaktion. Grammatik und Interaktion. Untersuchungen zum Zusammenhang von grammatischen Strukturen und Gesprächsprozessen, ed. by Arnulf Deppermann, Reinhard Fiehler and Thomas Spranz-Fogasy, 95-122. Radolfzell: Verlag für Gesprächsforschung.

Hohenstein, Christiane. 2006. Erklärendes Handeln im wissenschaftlichen Vortrag. Ein Vergleich des Deutschen mit dem Japanischen. München: Iudicium.

Kay, Paul, and Charles Fillmore. 1999. Grammatical Constructions and Linguistic

Generalizations: The What's X Doing Y? Construction. Language 75. 1-33.

Kay, Paul. 1997. Words and the Grammar of Context. Stanford, CA: CSLI.

Kiel, Ewald. 1999. Erklären als didaktisches Handeln. Würzburg: Ergon.

Klein, Josef. 2009. ERKLÄREN-WAS, ERKLÄREN-WIE, ERKLÄREN-WARUM. Typologie und Komplexität zentraler Akte der Welterschließung. Erklären. Gesprächsanalytische und fachdidaktische Perspektiven, ed. by Rüdiger Vogt, 25-36. Tübingen: Stauffenburg. 
Lakoff, George A. 1987. Women, Fire, and Dangerous Things. What Categories Reveal about the Mind. Chicago, IL: University of Chicago Press.

Langacker, Ronald W. 1987. Foundations of Cognitive Grammar, vol. 1. Stanford, CA: Stanford University Press.

Michaelis, Laura A. 2006. Construction Grammar. The Encyclopedia of Language and Linguistics, $2^{\text {nd }}$ edition, vol. 3, ed. by K. Brown. 73-84. Oxford: Elsevier.

Morek, Miriam. 2012. Kinder erklären. Interaktionen in Familie und Unterricht im Vergleich. Tübingen: Stauffenburg.

Rickheit, Gert; Sabine Weiss; Hans-Jürgen Eikmeyer. 2010. Kognitive Linguistik. Theorien, Modelle, Methoden. Tübingen: Francke.

Selting, Margret; Peter Auer; Birgit Barden et al. 1998. Gesprächsanalytisches Transkriptionssystem (GAT). Linguistische Berichte 173. 91-122.

Spreckels, Janet. 2009. Erklären im Kontext - neue Perspektiven. Erklären im Kontext. Neue Perspektiven aus der Gesprächs- und Unterrichtsforschung. ed. by Janet Spreckels, 1-10. Baltmannsweiler: Schneider Hohengehren.

Tomasello, Michael (ed.) 2003. The New Psychology of Language: Cognitive and Functional Approaches to Language Structure, vol. 2. Mahwah, NJ: Routledge. 